Trinity University

Digital Commons @ Trinity

Psychology Faculty Research

Psychology Department

1992

\title{
Improving Memory and Mood Through Automatic and Controlled Procedures of Mind
}

\author{
Paula T. Hertel \\ Trinity University, phertel@trinity.edu
}

Follow this and additional works at: https://digitalcommons.trinity.edu/psych_faculty

Part of the Psychology Commons

Publication Details

Memory Improvement: Implications for Memory Theory

\section{Repository Citation}

Hertel, P. T. (1992). Improving memory and mood through automatic and controlled procedures of mind. In D. J. Herrmann, H. Weingartner, A. Searleman, \& C. McEvoy (Eds.), Memory improvement: Implications for memory theory (pp. 47-65). Springer-Verlag. doi: 10.1007/978-1-4612-2760-1

This Contribution to Book is brought to you for free and open access by the Psychology Department at Digital Commons @ Trinity. It has been accepted for inclusion in Psychology Faculty Research by an authorized administrator of Digital Commons @ Trinity. For more information, please contact jcostanz@trinity.edu. 


\title{
Improving Memory and Mood Through Automatic and Controlled Procedures of Mind
}

\author{
Paula T. Hertel
}

Memory procedures and emotional states function together. Affective tone permeates episodes of memory functioning. Memory functions centrally in episodes of emotional disturbance, serving to feed the episode with fuel from past events or to repress those events when one hopes to escape or avoid the episode. When cognitive procedures are impaired by emotional states such as depression and anxiety, people do not perform the tasks and achieve the goals that could help to repair their moods. In the context of these considerations, then, we must view the improvement of memory as not merely a possible outcome of change in emotional states, but as a factor in effecting such change. Memory improvement and mood improvement function together.

In this chapter, I examine the relationship between memory functions and the negatively valenced emotional states of anxiety and depression. Isen (1984), Bower (1981), and others have discussed the relation of positively valenced states to memory, showing that a positive mood improves intentional memory for positive and sometimes neutral events. However, in a very practical sense, knowing that one can sometimes remember better in a good mood is trivial to the goal of memory improvement; the problem becomes one of trying to attain the good mood. Also, people in elated states don't care very much about possible memory difficulties that arise from extreme arousal or from attempts to recall negative events. In contrast, people care a great deal about impaired functions associated with depression and anxiety (Beck, Rush, Shaw, \& Emery, 1979; Poon, 1980). Furthermore, our knowledge of angry memory is limited, and it would seem to be a transitory phenomenon unless anger is accompanied by depression. These are the reasons for restricting my topic to depressive and anxiety-related phenomena in memory. The central goals in improving the memory functions of depressed and anxious people are restoration to nonnal levels and eventual mood repair. 
This chapter is organized according to the considerations noted at the outset. The first section briefly reviews the major findings in the literature on memory impairment associated with depression and anxiety. The emphasis is placed on findings that offer interesting implications for memory improvement. The second section pertains to memory improvement during mood impairment. Improving one's memory provides a reduction in the number of things one must feel depressed or anxious about. It also helps to achieve more important goals that might eventually assist in mood repair. The third section takes up the bidirectional relation of memory functioning and disturbed mood. In this section, I review the literature on cognitive biases associated with depression and anxiety, with an eye toward their alleviation. The third section is based on the assumptions that the best way to improve memory functioning is to repair the disturbed mood and that such repair involves important adjustments in memory procedures.

The literatures on mood-related effects in memory are guided by various theoretical perspectives (e.g., schema theory, network theory). Following the lead of others (e.g., Clark \& Isen, 1982; Eysenck, 1982; Hasher \& Zacks, 1979), I appeal to the theoretical distinction between automatic and controlled processes in order to establish a framework for this review. In the manner outlined by Kahneman (1973), I refer to procedures that can occur without attention or conscious awareness as automatic processes. Controlled processes are those that require attention or the use of resources that are essentially limited by a relatively fixed capacity for conscious thought. An emphasis on specific cognitive procedures holds the greatest promise for research on memory improvement (see Herrmann \& Searleman, 1990).

\section{Memory Impairment in Depressed and Anxious States}

Many reviews of mood and memory emphasize research on the association of mood with the emotional meaning of the materials or events to be remembered (i.e., mood congruence; e.g., Blaney, 1986; Ingram, 1984; Isen, 1984; Johnson \& Magaro, 1987). I briefly address issues related to mood congruence below, where I take up the interrelation between mood and memory improvement. Here I review research on memory impairment when depressed or anxious subjects encounter relatively neutral information. Relatively neutral materials probably constitute a large portion of what one encounters in occupational or educational settings.

Although symptoms of depression and anxiety correlate highly in some populations, there are potentially important differences in their effects on memory functions (Ingram, Kendall, Smith, Donnell, \& Ronan, 1987). Unfortunately, few researchers have taken measures of both types of affect, so the similarities and differences in the findings on depression and anxiety should be viewed with caution (see Greenberg \& Beck, 1989). Furthermore, the findings I review are gathered from different types of depressive populations (experimental inductions, dysphoric college students, outpatients with depressive symptoms and syndromes, and hospitalized depressives with and without other nosologies) and different types of anxious populations (students with test, state, or trait anxiety; phobics; and patients and students with other anxiety-related disorders). In my discussions of depressive and anxiety-related phenomena, I ignore possible differences associated with the type of population unless those differences have contributed to a reliable taxonomy of corresponding effects on memory functioning. For the most part, this has not been the case (cf., Ingram \& Kendall, 1987; Williams, Watts, Macleod, \& Mathews, 1988).

\section{Depressive Deficits}

A number of reviews of depressive deficits in memory conclude that depression is associated with a reduction in effortful or controlled processing within a limited capacity system (e.g., Ellis, \& Ashbrook, 1988; Williams et al., 1988). According to this view, depression depletes the resources needed to perform more difficult processing tasks. Depletion occurs through physiological limitations on processing capacity or through the allocation of attention to irrelevant features of self or context (Beck, 1967; Ellis \& Ashbrook, 1988). Depressed subjects in memory experiments, then, presumably have limited ability to employ controlled processes such as organization and elaboration--processes that require attention within the limited capacity system (see Hasher \& Zacks, 1979) and benefit subsequent attempts to remember.

Within this general framework of depressive deficits in controlled processing, some research has emphasized the organization (or the structure) of the materials to be remembered. Williams et al. (1988) and Ellis and Ashbrook (1988) have suggested that well structured or organized materials make fewer processing demands. Recall of clearly structured prose passages like those used by Hasher, Rose, Zacks, Sanft, and Doren (1985) does not reflect depressive deficits, whereas recall of more obtuse text does (see Watts \& Cooper, 1989). As early as 1976, Russell and Beekhuis showed that the ability to sort nouns into obvious categories during the learning task was not impaired by psychotic depression. Depressed patients in studies by Weingartner, Cohen, Murphy, Martello, and Gerdt (1981) showed recall deficits with unstructured word lists but not when the lists were clearly categorized. So in the sense of inherent structure of materials to be remembered, depressive deficits occur with poorly structured materials. Accounts of depressive deficits that emphasize depletions in resources tend to maintain that depressed subjects lack the resources to detect or to impose the structure that will benefit later recall.

Other specifications of impaired processing point to deficits in elaborative processing. Roy-Byrne, Weingartner, Bierer, Thompson, and Post (1986) 
found depressive deficits in recalling elaborated materials from a semantic orienting task but no deficit in frequency judgments, which are often not affected by elaborative processing.

Ellis, Thomas, and Rodriguez (1984, Experiment 1) showed that college students who were experimentally induced to feel depressed did not recall words that were each studied in elaborated sentences as well as did neutral subjects; perhaps they failed to expend the resources needed to fully process the elaborated contexts or to use them at the time of recall (see Ellis, Thomas, McFarland, \& Lane, 1985). In another experiment that employed induction procedures, Ellis et al. (1984, Experiment 3) showed a depressive deficit in recall of words placed in contextually difficult (less obvious) sentences but not in recall of words from sentences that were highly related to the words. Hertel and Rude (1991b) failed to replicate these findings with naturally depressed college students. (Also see Hasher et al., 1985; Ingram, 1989; Isen, 1984; for discussions of possible differences in memory effects associated with naturally occurring versus experimentally induced depression.) Recently, however, we have replicated the findings of Ellis et al. (1984, Experiment 3) with clinically depressed outpatients. The results of this experiment suggest moditications to previous speculations about the nature of depressive deficits in controlled processing.

In the incidental learning phase of an experiment by Hertel and Rude (1991a), outpatients exhibiting symptoms of unipolar depression, recovered outpatients, and nonpsychiatric controls judged the semantic fit of words into easy or difficult sentence frames. One learning condition was similar to the procedure of Ellis et al. (1984, Experiment 3): The word and the frame were displayed concomitantly, and subjects judged the fit whenever they chose to do so during the duration of the trial. Another condition restricted the display of the word to 1 second at the beginning of the trial; subjects were required to repeat the word and make the judgment at the end of the trial. In this second condition, then, the subjects' attention was focused on the task, in that they were required to rehearse the words and possibly encouraged to process them more elaboratively in the context of the sentence, whereas in the unfocused condition, subjects' attention was less constrained to focus on the task. The unfocused condition produced a depressive deficit in the subsequent free recall of words from the difficult contexts. In contrast, depressed subjects in the focused learning condition recalled those words as well as did both control groups.

Clearly, these results suggest that depression does not limit the ability to allocate sufficient resources to a more diflicult task. Yet an emphasis on controlled processes is still quite appropriate: When the task was unfocused, depressed subjects might have paid less attention to the materials; perhaps they allocated attention to task irrelevant processing. However, under focused learning conditions that were at least as demanding, depressed subjects performed as capably as nondepressed subjects. Hertel and Hardin (1990) describe deficits of the type that was demonstrated in the unfocused condition as depressive deficits in initiative. Unlike subjects in a neutral mood, depressed subjects fail to spontaneously initiate controlled processes that would benefit intentional remembering. When procedures are guided by instructions or when tests of memory bypass the advantage of uninstructed procedures employed spontaneously by nondepressed subjects, initiative ceases to be the issue and depressed subjects do not show memory impairments.

Deficits in initiative might be understood as difficulties in detecting the optimal strategy. Experiments by Leight and Ellis (1981), conducted with experimental inductions of depressive and neutral moods, have shown depressive impairments in the discovery of higher order structure for letter strings. In the varied-input condition, the learning task encouraged but did not instruct for the discovery of higher order meaning. In the constant-input condition, such discovery was made more difficult. Following the learning phase, subjects were transferred to a similar task with new letter strings, under either varied or constant conditions. The important result for the present purposes was that nondepressed subjects who received varied input on the learning task detected the higher order meaning and transferred that strategy to the second task, regardless of their mood or the conditions of input during the second task. A depressed mood prevented the detection of the optimal strategy, but once it had been discovered under neutral conditions, depressed subjects used the strategy effectively.

Depressive deficits in initiative might also be understood as motivational disturbances. Experimentally depressed subjects tend to report less curiosity and are less motivated to read about psychology experiments (Rodrigue, Olson, \& Markley, 1987). Riskind (1989) suggested that reduced interest in external events might even cause a reduction in the allocation of resources to cognitive tasks. Along these lines, Cohen, Weingartner, Smallberg, Pickar, and Murphy (1982) obtained a high correlation between sustained motor effort and recall at longer delays in a short-term memory task (for depressed subjects only). Because these tasks share few elements, the authors suggested that they are related through a central motivational state. Such a central mechanism could also determine the tendency to initiate strategies beyond the requirements of the task.

Retarded initiation of voluntary action is emphasized by Coyne and Gotlib's (1983) review of depression research. Similarly, Rehm (1982) related loss of initiative to deficits in self-monitoring and self-control. Retarded initiative, however, does not imply that depressed subjects simply suffer from low levels of arousal or lack incentives. Several investigators provide evidence that depressed people are ultimately very cooperative (Coyne \& Gotlib, 1983), that simple manipulations of incentive do not affect depressed subjects more than others (Richards \& Ruff, 1989), and that CNS arousal characterizes depression (e.g., Kuhl \& Helle, 1986). Clearly, the relation between depression and specific motivational constructs has not been well delineated.

Kuhl and Helle (1986) have developed an interesting approach to understanding the cooccurrence of central arousal and behavioral passivity in 
depression. They proposed that chronic depression is maintained by unfulfillable (degenerated) intentions. Intentions to achieve essentially unattainable goals use resources needed to enact new intentions. Thus, to the extent that they are "on one's mind," they induce arousal while ensuring passivity in ongoing tasks. One test of this account established a very minor unfulfillable goal (cleaning up a messy table) that, for depressed subjects only, seemed to remain active during subsequent tests of prospective memory (remembering to number pages) and memory span for words. Kuhl and Helle's work is compatible with the notion that ruminations occupy the cognitive capacity needed for ongoing tasks, but the ruminations are not necessarily self-related, and they interfere with the initiation of new tasks as well as with routine processing demands.

Finally, Watts, MacLeod, and Morris (1988b) suggest that the depressive mind is not always actively engaged in task irrelevant thoughts when deficits are observed in memory tasks. Mind wandering seems to occur during prose processing or retrieval, but when depressed subjects are engaged in planning during problem solving (e.g., the Tower of Hanoi) the mind "goes blank." Going blank seems to reflect difficulties in thinking about what to do next.

\section{Anxiety-Related Dericits}

In reviewing research on anxiety-related deficits in memory functions, Eysenck (1982) and Wine (1980) offered interpretations that emphasized attentional capacity. As in the hypothesis with depressive deficits, capacity is presumably occupied by extra-task processing. Unlike accounts of depressive deficits, however, Eysenck proposed that anxious subjects attempt to compensate with increased effort; they do better at easy tasks, while still showing the deficit in difficult tasks. Thus, anxiety reduces the reserve of resources for controlled processing, with arousal mediating the effects related to task difficulty. Moreover, arousal seems to have consequences for cue utilization (Easterbrook, 1959). Task irrelevant cues are eliminated by moderate levels of arousal, but higher levels seem also to eliminate more central, relevant cues (see Geen, 1980, for a review of cue utilization in test anxiety).

A particularly good summary of evidence of anxiety-related deficits in memory is provided by Williams et al. (1988, Ch. 3). Such deficits involve impaired elaboration, refcrred to by Williams et al. as biases toward surface level processing. Anxiety also seems to reduce the use of organizational processes, but such reduction sometimes is compensated for by other means. For example, Mueller (1976) has shown evidence of less clustering by anxious students without an overall deficit in free recall.

In general, anxiety-related deficits occur under conditions that are widely similar to those in which depressive deficits arise. Impaired elaborative and organizational processes are associated with susceptibility to sources of distraction that use resources within a limited capacity system. Ingram and
Kendall (1987) suggested that anxious subjects' task irrelevant focus is less self-oriented than what seems to be the case with depressives, but when the overlap between depression and anxiety is eliminated, so is the evidence for differences in self-focus (Ingram, 1990). Some anxious subjects, however, do show signs of excessive preoccupation with stressful situations and misperceive their demands (Ingram et al., 1987). They sometimes compensate by increasing their efforts on aspects of the task that are under their control (easier tasks that benefit from high levels of arousal).

Finally, it might be important to consider that almost all demonstrations of mood-related impairments have used tests of intentional remembering (see Jacoby \& Kelley, 1987). As has been found by Hertel and Hardin (1990), with depressed college students, mood impairments may not occur on tests where remembering is not the focus of attention but, instead, may occur in the course of performing other tasks. (Mood congruency, however, has been demonstrated in such tasks; these effects are described below.) Moreover, unintentional uses of memory clearly outdistance intentional uses of memory in their frequency and importance of occurrence. The irony of this observation lies in the realization that mood-impaired people are not aware that unintentional uses of memory may be unimpaired. They notice failures to remember when they are trying to remember. An important step in future research on memory impairment and complaints should be taken in the direction of exploring unintentional uses of memory by depressed and anxious people.

\section{Memory Improvement During Mood Impairment}

In their multimodal approach to suggestions for memory improvement, Herrmann and Searleman (1990) made distinctions between "content" manipulations, such as standard mnemonic techniques, and "process" manipulations, such as changes in emotional states. According to their view, process manipulations in the realm of depressive and anxiety-related deficits are somewhat synonymous with mood improvement (addressed in the next major section of this chapter). Evidence of mood dependent memory, also taken up briefly by Herrmann and Searleman, is mixed in the realm of depression and anxiety. Some researchers see mood dependent memory as a special case of mood congruency (e.g., Blaney, 1986); others doubt its existence or stress that it occurs only when other contextual cues are weak (e.g., Bower \& Mayer, 1989). Even if mood dependent memory turns out eventually to be a reliable phenomenon, we might wonder what it offers in the way of memory improvement techniques, beyond instructions to make one's mood during study comparable to one's mood during testing, or vice versa. In this section, then, I restrict my review to research on memory improvement in the realm of content and strategy manipulations used with depressed and anxious subjects. The aim is to find ways of improving memory performance 
to be used by people experiencing ongoing impaired moods.

The major question that arises in considering memory improvement techniques for depressed and anxious people is whether such improvement indeed is possible without mood repair. For example, after reviewing the evidence for depressive deficits in cognitive capacity, Williams et al. (1988, Chapter 3) wondered if depressed subjects are able to process "deeply;" some clinical studies have shown that depressives benefitted less than normals from inherent structure (i.e., the approximation of word lists to text). The implication is that depressed and anxious people should be resigned to function on low capacity as best they can. However, research that has focused on structuring not the materials but the task itself, through instructions and design, holds more promise for believing that people with impaired moods can engage the procedures that lead to good performance on memory tests. The advice that emerges from this research, described next, is to understand componentially the requirements of tasks to be completed by mood-impaired people, to construct methods for engaging the necessary procedures, and above all, not to abandon them to the weaknesses of their own initiative or to their irrelevant thoughts.

\section{Specific Procedures for Memory Improvement}

Because disturbances in the focus of attention characterize both types of mood impairments, it makes sense that there have been several successful attempts to improve memory by mobilizing the attention of depressed and anxious subjects for task appropriate processing. The evidence described above regarding the elimination of depressive deficits in recall by requiring attention to the target words during incidental learning (Hertel \& Rude, 1991a) is one example of such an attempt. Instructions to image during initial exposure to materials is yet another way. If subjects cooperate, imagery improves memory by way of both elaborative and organizational procedures. According to Watts, MacLeod, and Morris (1988a), imagery instructions improved severely depressed subjects' memory for prose, even though they still reported losses of concentration. Edmunson and Nelson (1976) showed that imagery instructions helped highly anxious students (as well as nonanxious students). In general, reviews of attempts to improve the performance of test anxious students on memory tasks (e.g., Geen, 1980) emphasize the importance of directing attention to task relevant features and away from sources of distraction.

Directing attention away from sources of distraction experienced by depressed people can be achieved by increasing task demands. Krames and MacDonald (1985) obtained this result in a dual-processing task with varying degrees of cognitive load. Nondepressed subjects recalled more words from the beginning of lists under low loads than under high loads, but the reverse was true for the depressed outpatients, who showed a "distraction effect" under low loads and recalled at higher levels as load increased. Ruminations apparently can be overridden by attention-demanding tasks.

Attention-demanding tasks, of course, do not necessarily mobilize attention in ways that benefit memory performance. Many tasks are susceptible to the use of special strategies that are not specified by instructions. Hertel and Hardin (1990), for example, emphasized the importance of guiding depressed subjects in their use of controlled strategies for recognition. In these experiments, experimentally depressed, naturally depressed, and nondepressed college students completed two different tests of memory for homophones whose less frequent meanings (e.g., pear instead of pair) had been biased in an incidental study phase. In the first test of memory (spelling), the number of homophones spelled in line with the studied bias indexed the unintentional use of memory and did not show a depressive deficit. Tests of unintentional uses of memory typically do not show effects of elaborative learning or invite strategic procedures during testing, and so nondepressed subjects should not show the advantage of initiating unrequired procedures. Tests of intentional remembering, such as recognition, are susccptible to uninstructed procedures, and on the following test of recognizing homophones from the study phase, depressive deficits were revealed. Specifically, nondepressed subjects tended to use strategies for recognition that employed the intervening spelling test, whereas recognition and spelling were stochastically independent for depressed subjects. Most important for research on memory improvement were the results from attempts to provide all subjects with strategies that might have been employed spontaneously by nondepressed subjects. When they were directed to recall the study phase as they spelled (Experiment 2) or to use their performance on the spelling test as a bridge to the study phase during recognition (Experiment 3), the recognition performance of depressed subjects improved.

The investigation of impairments in strategic processing has been the focus of research on problem solving in depression. Silberman, Weingartner, and Post (1983) found that depressed subjects focused less on a single hypothesis than did nondepressed subjects and solved fewer problems. Yet, when they were required to list their hypotheses while solving, depressed subjects improved. Similarly, Abramson, Alloy, and Rosoff (1981) discovered that when depressed subjects were provided with hypotheses for problem solving, they performed as well as normals.

In summary, we might conclude that depressed people can be helped to perform well on tests of intentional remembering if they are required to attend to task relevant features and guided to employ appropriate strategies. Although anxious pcople probably do not suffer from the lack of initiative, they nevertheless need help in focusing on the relevant features of the task. One might surmise from the comments of Ingram and Kendall (1987) and Wine (1980) that anxious people would also profit from specifications of strategies for unstructured situations. Yet, what can be done more generally 
in memory-training programs to encourage depressed and anxious people to develop skills for use beyond the task at hand?

\section{Memory Training}

According to Williams et al. (1988, Ch. 3), there have been few, if any, demonstrations of long-term instructional effects for depression and anxiety. Poon (1980) outlined a multifaceted program that includes specific suggestions for practicing learning strategies and for developing retrieval plans. Yet, as Watts et al. (1988a) aptly comment, "the main challenge is likely to be getting [depressed people] to actually use the strategies" (p. 187). No one (depressed, anxious, or "normal" people alike) likes to use the effortful, controlled procedures that typify memory improvement techniques. Indeed, Poon's program includes many motivational components to encourage practice.

Long-term improvement in the real world also depends heavily on what one might call "prospective metamemory." Practiced and skilled we may be, but we still must consciously remember to use the techniques, at least until they become automatic or habitual. Prospective metamemory might be best achieved if training and practice take place in a variety of settings and tasks so that cues to use the procedures are linked to the situations in which they are needed.

Finally, it seems likely that a stable of mnemonic and search techniques might not be the thing to emphasize in training programs with depressed and anxious people. What seems to be particularly necessary is practice at staying on task, perhaps assisted by external aids. Training in breaking down the components of cognitive tasks might help to override depressive deficits in initiative and planning. In this regard, main-line research on memory might do well to emphasize specific procedures of mind (Kolers \& Roediger, 1984). Functional approaches, such as the description of relations among classes of cues (Watkins, 1990), offer direct application to memory training.

Any program designed to improve memory functions in the long run must also consider factors beyond training in specific skills and strategies (Poon, 1980). For example, a reduced sense of self-efficacy in cognitive tasks is associated with depressed moods (Bower, 1983) and test anxiety (Wine, 1980) Self-efficacy determines what one attempts to do and how well one persists in doing it (Bandura, 1977). Therefore, training in self-efficacy--through experience in structured tasks--might help to improve performance on unstructured memory tasks (also see Hertzog, this volume). In addition, Kuhl and Helle (1986) advised that we teach depressed people strategies for disregarding intentions unrelated to the task at hand.

\section{Improvement in Mood and Memory}

Improvement in memory functioning of mood-impaired people seems best achieved by repairing the disturbed moods. Does mood repair actually help? Our assumption that it does relies on evidence that mood-impaired subjects do not perform as well as others. Most of these studies are correlational; even in the ones that employ experimental inductions, some other phenomenon associated with the induced mood may actually cause the deficit (see Riskind, 1989). What is needed is research in which mood-impaired subjects are randomly assigned to treatments for mood repair or to wait lists, with a demonstration of pretreatment deficits and posttreatment recovery.

If mood repair does improve memory performance, the method of treatment seems to be critical. For example, remediation of memory difficulties associated with test anxiety has not been achieved reliably by treating the emotional component of anxiety through relaxation techniques (see Williams et al., 1988, Ch. 3; Wine, 1980). Furthermore, one cannot repair mood disturbances without involving memory functions. The success of attempts at mood repair is clearly affected by ongoing memory procedures such as mood congruent attention and retrieval.

Selective attention to mood congruent aspects of current experience and selective remembering of mood congruent aspects of events from the past constitute ubiquitous findings in the literature on mood and memory (see reviews by Blaney, 1986; Bower, 1981; Isen, 1984; Johnson \& Magaro, 1987). However, the selectivity of these procedures is commonly thought to be an automatic aspect of feeling state, with controlled processes operating on the material that is automatically selected for attention (Clark \& Isen, 1982; but see the superb critique by Blaney, 1986). Mood is presumably maintained by automatic selection and repaired by controlled processes. Sometimes controlled processes such as active rehearsal of mood-related materials are thought to operate in such a way as to reconcile their meaning and achieve self-control (e.g., Rehm, 1982); sometimes controlled processes direct attention away from further processing and toward more neutral material. Next, I describe a few examples of mood congruent effects that illustrate these proposed phenomena.

In the realm of automatic selection, several studies (reviewed by Williams et al., 1988, Ch. 10) have shown selective attention to threat-related words by anxious subjects. Also, Eysenck, Macleod, and Mathews (1987), for example, showed that trait anxious subjects spelled homophones in the direction of threat-related meaning (e.g., die vs. dye). Similar effects have been found in depression; for example, a depressed mood has been associated with lowered thresholds for detecting failure-related words (Postman \& Brown, 1952) and emotional words in general (Small \& Robins, 1988). Yet, according to Williams et al., depressive effects in automatic selection have not been demonstrated when anxiety is controlled. 
Automatic retrieval processes, to the extent to which they characterize procedures in tests of unintentional memory, also are implicated in anxiety. Subjects in a study by Mathews, Mogg, May, and Eysenck (1989) were asked to imagine scenes for threatening and nonthreatening words and to judge their pleasantness. Later they were provided with three-letter stems for old and new words and told to complete them with the first word that came to mind. Subjects with generalized anxiety disorders completed the stems of old threatening words more often than other types and more often than did controls. In the controlled-processing test of cued recall, however, anxiety-related differences were not obtained. Furthermore, others cited by Mathews et al. have found that anxious subjects actually recall fewer threatening than nonthreatening words. Perhaps controlled processes operate to avoid further processing of threatening materials.

Illustrations of mood congruent effects on intentional recall abound. Symmetries with respect to depression and anxiety are most often found when materials have been processed self-referentially (e.g., Greenberg \& Beck, 1989; Ingram et al., 1987). Such symmetries led Ingram and Kendall (1987) to suggest that anxious and depressed subjects engage similar procedures, with the products of the procedures exhibiting differences associated with the type of mood. Others might point out that controlled procedures operate to different ends, as a consequence of motivational factors such as avoidance (in anxiety) or mood repair (in depression). We can reasonably assume that controlled procedures would be involved in attempts at mood control. Such attempts would not always be important in typical experimental contexts (and therefore symmetries between depression and anxiety can be demonstrated), but they would more likely arise in natural contexts for retrieving personal memories (see Costanzo \& Hasher, 1989).

A framework for reconciling the sometimes disparate findings on mood congruency has been offered by Williams et al. (1988, Chapter 10). Their model holds that depression and anxiety involve different types of biases in specific procedures that are either passive (automatic) or awareness based (controlled). Anxiety operates like automatic priming in moving resources loward threatening materials. Later, awareness-based procedures direct resources away from threatening materials, thereby inhibiting the development of cues for recall. In contrast, depression biases the products of controlled processes by deploying resources to the recruitment of depression-related information. The model provides links to certain notions of adaptation: Anxiety helps people to avoid danger, so automatic aspects of information processing are sensitive to anxiety; one function of depression is to come to terms with loss, so controlled procedures are sensitive to depression.

Based on their model, Williams et al. (1988) provide some suggestions for remediation of impaired mood. Treatments that emphasize positive aspects of experience can, through rehearsal, make them more likely to be automatically selected. Furthermore, treatment may help mood-impaired people to become aware of the ways that automatic processes contribute to their mood states.
Such awareness might not directly modify the state, but it could provide opportunities for the counterconditioning of emotional processes. For example, if threatening stimuli are not avoided, reactions other than fear can be conditioned and erroneous ideas about threat can be challenged (see Foa \& Kozak, 1986). A similar point is made by Beck et al. (1979): By concentrating attention on "automatic" negatively valenced thoughts, depressed people could then redirect resources to more productive focal points and those procedures might become more automatic with practice.

More generally, cognitive therapies have been shown to be effective in the treatment of depression (e.g., Teasdale, Fennell, Hibbert, \& Amies, 1984) and the "worry" component of anxiety (Wine, 1980). Cognitive therapies include techniques of cognitive restructuring of depressive or worrisome thoughts. Teasdale (1983) tells us that cognitive therapy helps the client to gain access to more realistic thoughts; such access can be attained through the guidance of thoughts or the improvement of mood, which provides automatic access to positive thoughts. The processes involved in restructuring might well involve redirecting resources to more productive thoughts in both conscious and unconscious ways (Williams et al., 1988, Chapter 10).

\section{Conclusions}

In reviewing what we have learned to date about memory improvement, Herrmann and Searleman (1990) reached three conclusions. First, people will not continue to use very effortful techniques. According to some formulations, the use of such techniques by depressed and anxious people is inherently limited by their moods. Alternatively, my review has led to the conclusion that the attention of depressed and anxious people can be mustered for effortful processing by structuring the requirements of the task. This capability, however, does not obviate the problems associated with long-term improvement in intentional remembering. Some remediation might be achieved through training in prospective metamemory, which would require a clearer understanding of functional aspects of memory.

Functional analyses emphasize specific aspects of the task under consideration. Similarly, Herrmann and Searleman's (1990) second conclusion was that memory training should focus on skills that are specitic to the materials and task at hand. The notion of specilicity should also be extended to the domain of mood-related impairments, such as difficulties in planning and in attending to task-related cues.

Third, the focus of memory training should be "multimodal." One of the modes addressed by Herrmann and Searleman (1990) is the emotional state of the rememberer. The authors suggest that various modes operate in ways that are both central and peripheral to the memory system. This observation clearly holds for depressive and anxious memory. Impaired moods perhaps function peripherally to affect motivations associated with planning and task 
initiation. Impaired moods function centrally to channel the focus of attention, sometimes away from the task and sometimes toward mood-related aspects of experience. The distribution of resources to mood-related material may function to maintain the mood and associated memory problems, but it can be used therapeutically to repair the mood by summoning controlled processes in situations where automatic processes typically hold sway.

Gaining control seems to be what memory training is all about. In contrast, losing control by practicing to make effortful procedures automatic (Klatzky, 1984) or by using memory unconsciously (Jacoby \& Kelley, 1987) might turn out to be better advice to give depressed and anxious people. Because we rarely consider the unconscious effects of past experience, memory complaints surely are based on failures to intentionally remember. Who knows what deleterious effects are exerted by beliefs about impaired memory and the concomitant resolution to try harder? Unless the depressed or anxious person understands specifically how to improve memory, trying harder to remember may merely exacerbate the impairment by providing more salient examples of failure that increase anxiety and depression.

\section{Endnote 1}

The writing of this chapter was supported by Grant \#RO3 MH44044 from the National Institute of Mental Health.

\section{References}

Abramson, L.Y., Alloy, L., \& Rosoff, R. (1981). Depression and the generation of complex hypotheses in the judgment of contingency. Behavior Therapy and Research, 19, 35-45.

Bandura, A. (1977). Self-efficacy: Toward a unifying theory of behavior change. Psychological Review, 84, 191-215.

Beck, A.T. (1967). The diagnosis and management of depression. Philadelphia: University of Pennsylvania Press.

Beck, A.T., Rush, A.J., Shaw, B.F., \& Emery, G. (1979). Cognitive therapy of depression. New York: Wiley.

Blaney, P.H. (1986). Affect and memory: A review. Psycloological Bulletin, 99, 229-246.

Bower, G.H. (1981). Mood and memory. American Psychologist, 36, 129-148. Bower, G.H. (1983). Affect and cognition. Philosophical Transactions of the Royal Society of London, B302, 387-402.

Bower, G.H., \& Mayer, J.D. (1989). In search of mood-dependent retrieval. In D. Kuiken (Ed.), Mood and memory: Theory, research, and applications [Special Issue]. Joumal of Social Behavior and Personality, 4, 121.156.
Clark, M.S., \& lsen, A.M. (1982). Toward understanding the relationship between feeling states and social behavior. In A.H. Hastorf \& A.M. Isen (Eds.), Cognitive social psychology (pp. 73-108). New York: Elsevier.

Cohen, R.M, Weingartner, H., Smallberg, S.A., Pickar, D., \& Murphy, D.L. (1982). Effort and cognition in depression. Aichives of General Psychiatry, 39, 593-597.

Costanzo, P.R., \& Hasher, L. (1989). Mood and memory: A reconsideration. In D. Kuiken (Ed.), Mood and memory: Theory, research, and applications [Special Issue]. Joumal of Social Behavior and Personality, 4, 71-78.

Coyne, J.C., \& Gotlib, I.H. (1983). The role of cognition in depression: A critical appraisal. Psychological Bulletin, 94, 472-505.

Easterbrook, J.A. (1959). The effect of emotion on cue utilization and the organization of behavior. Psychological Review, 66, 183-201.

Edmunson, E.D., \& Nelson, D.L. (1976). Anxiety, imagery, and sensory interference. Bulletin of the Psychonomic Society, 8, 319-322.

Ellis, H.C., \& Ashbrook, P.W. (1988). Resource-allocation model of the effects of depressed mood states on memory. In K. Fiedler \& J. Forgus (Eds.), Affect, cognition, and social behavior: New evidence and integrative attempts (pp. 25-43). Toronto: Hogrefe.

Ellis, H.C., Thomas, R.L., McFarland, A.D., \& Lane, W. (1985). Emotional mood.states and retrieval in episodic memory. Joumal of Experimental Psychology: Learning, Memory, and Cognition, 11, 363-370.

Ellis, H.C., Thomas, R.L., \& Rodriguez, I.A. (1984). Emotional mood states and memory: Elaborative encoding, semantic processing, and cognitive effort. Joumal of Experimental Psychology: Leaming, Memory, and Cognition, 10, 470-482.

Eysenck, M.W. (1982). Attention and arousal: Cogrition and perfomance. New York: Springer-Verlag.

Eysenck, M.W., MacLeod, C., \& Mathews, A. (1987). Cognitive functioning in anxiety. Psychological Research, 49, 189-195.

Foa, E.B., \& Kozak, M.J. (1986). Emotional processing of fear: Exposure to corrective information. Psychological Bulletin, 99, 20-35.

Geen, R.G. (1980). Test anxiety and cue utilization. In I.G. Sarason (Ed.), Test anxiety: Theory, research, and applications (pp. 43-62). Hillsdale, NJ: Erlbaum.

Greenberg, M.S., \& Beck, A.T. (1989). Depression versus anxiety: A test of the content-specificity hypothesis. Joumal of Abnornnal Psychology, 98, 9-13.

Hasher, L., Rose, K.C., Zacks, R.T., Sanft, H., \& Doren, B. (1985). Mood, recall, and selectivity effects in normal college students. Joumal of Experimental Psychology: General, 114, 104-118.

Hasher, L., \& Zacks, R.T. (1979). Automatic and effortful processes in memory. Joumal of Experimental Psychology: General, 108, 356-388.

Herrmann, D.J., \& Searleman, A. (1990). The new multi-modal approach to memory improvement. In G. Bower (Ed.), Advances in learning and motivation (Vol. 26, pp. 175-205). New York: Academic Press. 
Hertel, P.T., \& Hardin, T.S. (1990). Remembering with and without awareness in a depressed mood: Evidence for deficits in initiative. Joumal of Experimental Psychology: General, 119, 45-59.

Hertel, P.T., \& Rude, S.S. (1991a). Depressive deficits in memory: Focusing attention improves subsequent recall. Jounal of Experimental Psychology: General, 120, 301-312.

Hertel, P.T., \& Rude, S.S. (1991b). Recalling in a state of natural or experimental depression. Cognitive Therapy and Research, 15, 103-127.

Ingram, R.E. (1984). Toward an information-processing analysis of depression. Cognitive Therapy and Research, 8, 443-478.

Ingram, R.E. (1989). External validity issues in mood and memory research. In D. Kuiken (Ed.), Mood and memory: Theory, research, and applications [Special Issue]. Jounal of Social Behavior and Personality, 4, 57-62.

Ingram, R.E. (1990). Attentional nonspecificity in depressive and generalized anxious affective states. Cognitive Therapy and Research, 14, 25-35.

Ingram, R.E., \& Kendall, P.C. (1987). The cognitive side of anxiety. Cognitive Therapy and Research, 11, 523-536.

Ingram, R.E., Kendall, P.C., Smith, T.W., Donnell, C., \& Ronan, K. (1987). Cognitive specificity in emotional distress. Joumal of Personality and Social Psychology, 53, 734-742.

Isen, A.M. (1984). Toward understanding the role of affect in cognition. In R. Wyer \& T. Srull (Eds.), Handbook of social cognition (Vol. 3, pp. 179-236). Hillsdale, NJ: Erlbaum.

Jacoby, L.L., \& Kelley, C.M. (1987). Unconscious influences of memory for a prior event. Personality and Social Psychology Bulletin, 13, 314-336.

Johnson, M.H., \& Magaro, P.A. (1987). Effects of mood and severity on memory processes in depression and mania. Psychological Bulletin, 101, 28-40.

Kahneman, D. (1973). Attention and effort. Englewood Cliffs, NJ: Prentice-Hall.

Klatzky, R.L. (1984). Menory and awareness: An infomation-processing perspective (p. 137). New York: Freeman.

Kolers, P.A., \& Roediger, H.L., III (1984). Procedures of mind. Joumal of Verbal Leaming and Verbal Behavior, 23, 425-449.

Krames, L., \& MacDonald, M.R. (1985). Distraction and depressive cognitions. Cognitive 77erapy and Research, 9, 561-573.

Kuhl, J., \& Helle, P. (1986). Motivational and volitional determinants of depression: The degenerated-intention hypothesis. Joumal of Abnomnal Psychology, 95, 247-251.

Leight, K.A., \& Ellis, H.C. (1981). Emotional mood states, strategies, and state dependency in memory. Joumal of Verbal Leaming and Verbal Behavior, 20, 251-266.

Mathews, A., Mogg, K., May, J., \& Eysenck, M. (1989). Implicit and explicit memory bias in anxiety. Jounal of Abnonnal Psychology, 98, 236-240.

Mueller, J.H. (1976). Anxiety and cue utilization in human learning and memory. In M. Zuckerman \& C.D. Spielberger (Eds.), Enotions and anxiety: New concepts, methods and applications (pp. 197-229). Hillsdale, NJ: Erlbaum.

Poon, L.W. (1980). A systems approach for the assessment and treatment of memory problems. In J.M. Ferguson \& C.B. Taylor (Eds.), The comprehensive handbook of behavioral medicine (Vol. 1, pp. 193-212). New York: Spectrum.

Postman, L., \& Brown, D.R. (1952). Perceptual consequences of success and failure. Joumal of Abnonnal and Social Psychology, 47, 213-221.

Rehm, L.P. (1982). Self-management in depression. In P. Karoly \& F.H. Kanfer (Eds.), Self-managentent and behavior change: From theory to practice (pp. 522-567). New York: Pergamon.

Richards, P.M., \& Ruff, R.M. (1989). Motivational effects on neuropsychological functioning: Comparison of depressed versus nondepressed individuals. Jounal of Consulting and Clinical Psychology, 57, 396-402.

Riskind, J.H. (1989). Will the field ultimately need a more detailed analysis of mood-memory? In D. Kuiken (Ed.), Mood and memory: Theory, research, and applications [Special Issue]. Jounial of Social Behavior and Personality, 4, 39-44.

Rodrigue, J.R., Olson, K.R., \& Markley, R.P. (1987). Induced mood and curiosity. Cognitive 77erapy and Research, 11, 101-106.

Roy-Byrne, P.P., Weingartner, H., Bierer, L.M., Thompson, K., \& Post, R.M. (1986). Effortful and automatic cognitive processes in depression. Archives of General Psychiatry, 43, 265-267.

Russell, P.W., \& Beekhuis, M.E. (1976). Organization in memory. Joumal of Abnormal Psychology', 85, 527-534.

Silberman, E.K., Weingartner, H., \& Post, R.M. (1983). Thinking disorder in depression. Archives of General Psychiaty, 40, 775-780.

Small, S.A., \& Robins, C.J. (1988). The influence of induced depressed mood on visual recognition thresholds: Predictive ambiguity of associative network models of mood and cognition. Cognitive 7herapy and Research, 12, 295-306.

Teasdale, J.D. (1983). Negative thinking in depression: Cause, effect, or reciprocal relationship? Advances in Behaviour Research and Therapy, 5, 27-49.

Teasdale, J.D., Fennell, M.J.V., Hibbert, G.A., \& Amies, P.L. (1984). Cognitive therapy for major depressive disorders in primary care. British Jounal of Psychiaty, 144, 400-406.

Watkins, M.J. (1990). Mediationism and the obfuscation of memory. Anmerican Psychologist, 45, 328-335.

Watts, F.N., \& Cooper, Z. (1989). The effects of depression on structural aspects of the recall of prose. Joumal of Abnonnal Psychology, 98, 150-153.

Watts, F.N., Macleod, A.K., \& Morris, L. (1988a). A remedial strategy for memory and concentration problems in depressed patients. Cogritive 77herapy and Research, 12, 185-193. 
Watts, F.N., MacLeod, A.K., \& Morris, L. (1988b). Associations between phenomenal and objective aspects of concentration problems in depressed patients. British Joumal of Psychology, 79, 241-250.

Weingartner, H., Cohen, R.M., Murphy, D.L., Martello, J., \& Gerdt, C. (1981). Cognitive processes in depression. Archives of General Psychiatry, $38,42-47$.

Williams, J.M.G., Watts, F.N., MacLeod, C., \& Mathews, A. (1988). Cognitive psychology and enotional disorders. New York: Wiley.

Wine, J.D. (1980). Cognitive-attentional theory of text anxiety. In I.G. Sarason (Ed.), Test anxiety: Theory, research, and applications (pp. 349-385). Hillsdale, NJ: Erlbaum. 